\title{
Relationships between lightning and rainfall intensities during rainy events in Cyprus
}

\author{
S. Michaelides, K. Savvidou, and K. Nicolaides \\ Meteorological Service, Nicosia, Cyprus
}

Received: 11 March 2009 - Revised: 21 June 2010 - Accepted: 28 July 2010 - Published: 25 August 2010

\begin{abstract}
The objective of this work is to study the relationship between the number of lightning recorded by a network of lightning detectors and the amount of rainfall recorded by the network of automatic rain gauges, during rainy events in Cyprus. This study aims at revealing possible temporal and spatial "relationships" between rainfall and lightning intensities. The data used are based on the available records of hourly rainfall data and the "associated" lightning data, with respect to both time and space. The search for temporal and spatial relationships between lightning and rainfall is made by considering various time-lags between lightning and rainfall, and by varying the area around the rain gauge which the associated lightning data set refers to. The methodology adopted in this paper is a statistical one and rainy events registered under the European Project "FLASH" are examined herein.
\end{abstract}

\section{Introduction}

A measurement of the electrical activity of thunderstorms is achieved by counting the number of lightning flashes and evaluating the flash density within a certain area. Such lightning location systems have been operating all over Europe and the Mediterranean since the middle of the past century (at that time, the recorded flashes were better known as "spherics"). The ZEUS lightning system is a modern network of 5 land-based lightning detector stations (Fig. 1). One of these land stations is in operation at Larnaka Meteorological Office, located on the southeast coast of Cyprus, since 2002. ZEUS has a very good coverage of the area of the Eastern Mediterranean; the system is administrated and the data are

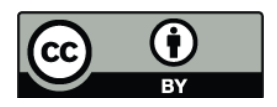

Correspondence to: S. Michaelides (silas@ucy.ac.cy) archived by the National Observatory of Athens (NOA), in Greece (see Lagouvardos et al., 2009).

The link between lightning and rainfall has been documented by researchers for many years (see Uman, 1987, for a historical review of lightning studies). Techniques for directly estimating rainfall from cloud-to-ground (CG) lightning observations have also been explored by previous investigators (see Piepgrass and Krider, 1982). In thunderstorms, a correlation between the temporal evolution of lightning and rainfall is supported by many studies (e.g., Ezcurra et al., 2002). In the vast majority of the thunderstorms studied, it was generally postulated that an increase in rainfall corresponded to an increase in lightning activity. Furthermore, from a spatial point of view, cloud-to-ground (CG) flashes are generally found to occur close to the area where the heaviest precipitation occurs (Soula et al., 1998). Also, many studies reveal a time-lag of a few minutes between lightning and rain initiation (Soula et al., 1998) or between the peak flash rate and the maximum rain rate (Altaratz et al., 2003).

In a study by Lang and Rutledge (2002), the complexity of the lightning evolution was revealed by studying the cloud lightning output as a function of the storm's kinematics and microphysics. Rivas Soriano et al. (2001) studied the relationship between CG lightning and convective precipitation over the Iberian Peninsula during the warm season; they realized that convective precipitation and CG lightning show a similar spatial distribution and demonstrated that the quantification of a relationship between CG lightning and surface precipitation is possible.

Tapia et al. (1998) have demonstrated the potential use of lightning as a short-term predictor of flash floods produced by localized intense convection.

For the purpose of identifying possible relationships between lightning and rainfall, lightning data (provided by NOA) concerning nineteen rainy events in Cyprus were spatially and statistically related to respective rainfall measurements acquired from the rain gauge network of the Cyprus

Published by Copernicus Publications on behalf of the European Geosciences Union. 


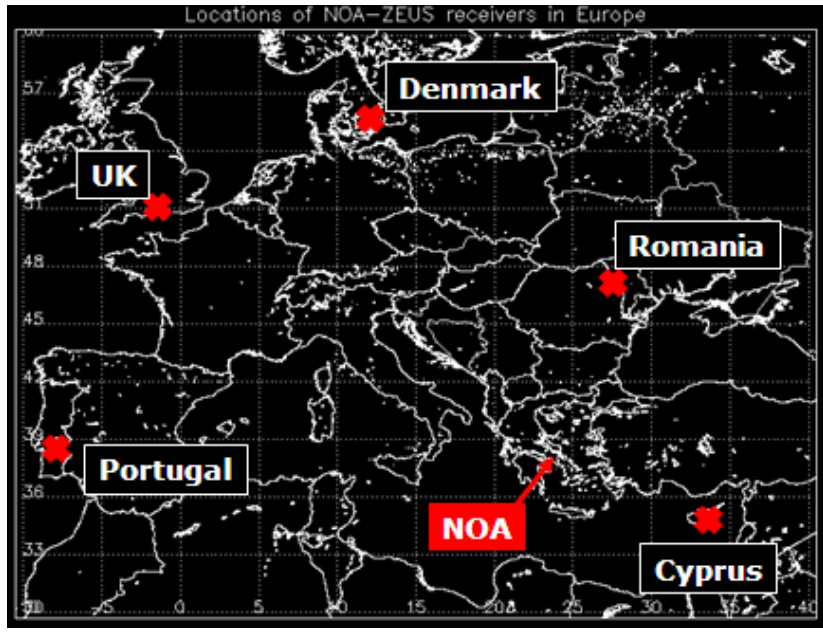

Fig. 1. The ZEUS lightning network.

Meteorological Service. A scheme of time-lag variation between lightning and rainfall, as well as a scheme of area variation around the weather stations which the associated lightning data set is referring to, was used. The use of a timelag as described above is supported by observations and the values adopted herein are within the acceptable range (see Gungle and Krider, 2006).

The present study is a continuation and extension of previously published results reached by using a rectangular methodology (see Michaelides et al., 2009).

\section{Data}

The study area is the area of Cyprus bounded by the meridians $32^{\circ}$ and $34.5^{\circ} \mathrm{E}$ and the parallel circles $34.4^{\circ}$ and $35.8^{\circ} \mathrm{N}$. The rainfall data are obtained from the network of thirty-three rain gauges of the Meteorological Service of Cyprus (Fig. 3). Not all the rain gauges were used for every rainy event, since precipitation measurements were not always readily available due to gaps in the data or rain gauge malfunctioning. Lightning data retrieved from the ZEUS system were provided by the National Observatory of Athens (NOA) in Greece (an assessment of the performance of the ZEUS system has been presented by Morales et al., 2007, and, more recently, by Kotroni and Lagouvardos, 2008, and Lagouvardos et al., 2009).

\section{Methodology}

The aim of the present study was to identify possible relationships between rainfall and lightning activity in a certain geographical area. For this purpose, a certain methodology was adopted and implemented, the main steps of which are briefly described in the following.

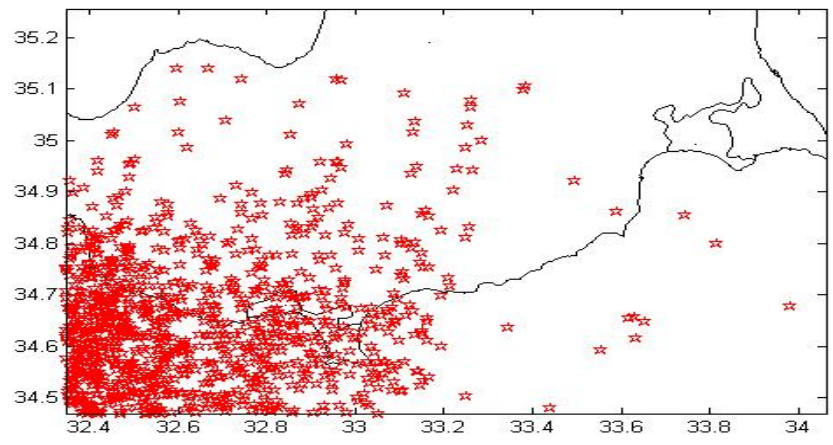

Fig. 2. Lightning data for the event on 18 October 2006.

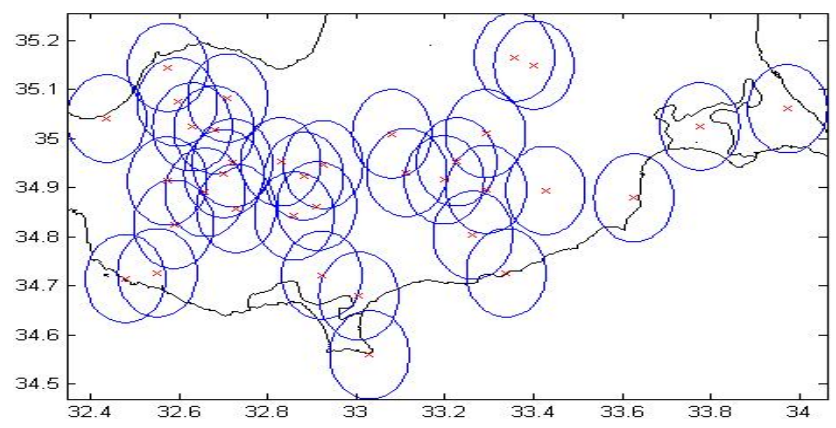

Fig. 3. Rainfall stations with precipitation of more than $5 \mathrm{~mm}$, concerning the event on 18 October 2006; the radius defining the area around each station is $10 \mathrm{~km}$.

At first, the hourly rainfall data concerning the nineteen rain events and the associated hourly lightning datasets were gathered. The relZeus software, developed by another "FLASH" partner, namely, GAMA (Meteorological Hazards Analysis Team, Department of Astronomy \& Meteorology, Faculty of Physics, University of Barcelona, Spain) was subsequently used, in order to derive possible relationships between the recorded rainfall at a certain station and the lightning activity reported within a circular area. The above software "tags" lightning data (characterized by specific time and geographical location) to a specific area with the rain station at its center and a variable radius (an example of a case study is given in Figs. 2 and 3) providing a graphical representation of the relationship, as well as calculating the correlation coefficient between the two sets of data. A time-lag between rainfall data and lightning activity within the circle of the relevant station of 5, 10 and $15 \mathrm{~min}$ was also set. In the present study, with a time-lag of 5, 10 and 15 min between rain and lightning data, the rainfall recorded from 02:00 until 03:00 UTC was associated with the lightning recorded in the time period 01:55-02:55, 01:50-02:50 and 01:45-02:45 UTC, respectively.

A filter was also applied to the rainfall data, excluding from the calculations those stations that recorded rainfall less than $5 \mathrm{~mm}$ per hour; this was adopted in an attempt to limit 
Table 1. The six schemes resulting from the various combinations of radius and time lags used in the present analysis.

\begin{tabular}{llll}
\hline $\begin{array}{l}\text { Time lag } \\
\text { Radius }\end{array}$ & 5 min & 10 min & 15 min \\
\hline $10 \mathrm{~km}$ & $5-\mathrm{R} 10$ & $10-\mathrm{R} 10$ & $15-\mathrm{R} 10$ \\
$15 \mathrm{~km}$ & $5-\mathrm{R} 15$ & $10-\mathrm{R} 15$ & $15-\mathrm{R} 15$ \\
\hline
\end{tabular}

the study to those cases with heavier precipitation which are most likely to be associated with lightning.

After applying the filter and by varying the radius (10 or $15 \mathrm{~km}$ ) around the rainfall measuring station and varying the time-lag between rainfall and lightning activity $(5,10$ or $15 \mathrm{~min}$ ), six schemes of rainfall stations and lightning data were established and subsequently used with the relZeus software for extracting the relationships. These six schemes are presented in Table 1.

For each of the above six schemes, a regression line between the amount of rainfall and the corresponding number of lightning, as well as the correlation coefficient, were calculated. An example of the results for a case study is shown in Fig. 4.

\section{Results and discussion}

In its present form, the software that was developed does not attempt to fit any other relationship but a linear one; thus for each event, regression lines are fitted to rainfall and lightning data for a radius of 10 and $15 \mathrm{~km}$ and for a time lag (between accumulated rainfall and the subsequent lightning strikes) of 5, 10 and $15 \mathrm{~min}$, accordingly. A basic statistical analysis of the characteristics of the regression lines of the nineteen rainy events was performed concerning the slope of the regression line and the correlation coefficient as functions of the radius and the time lag.

\subsection{Slope of the regression line}

A linear regression was fitted to the lightning/rainfall data and the sign of its slope is studied in this sub-section: a positive (negative) sign indicates that rainfall increases (decreases) with an increase in the number of lightning. Figure 5 shows that both positive and negative slopes were found for all of the six schemes of Table 1. The slope of the regression lines for nine of the events was positive, while for five events it was negative, irrespective of the radius and time lag.

In an attempt to explain why such negative slopes are possible with the data and methodology used here, the following considerations were made.

The nineteen events studied here were classified into two groups: eleven belong to the cold period (October to April) and eight belong to the warm period (May to September).

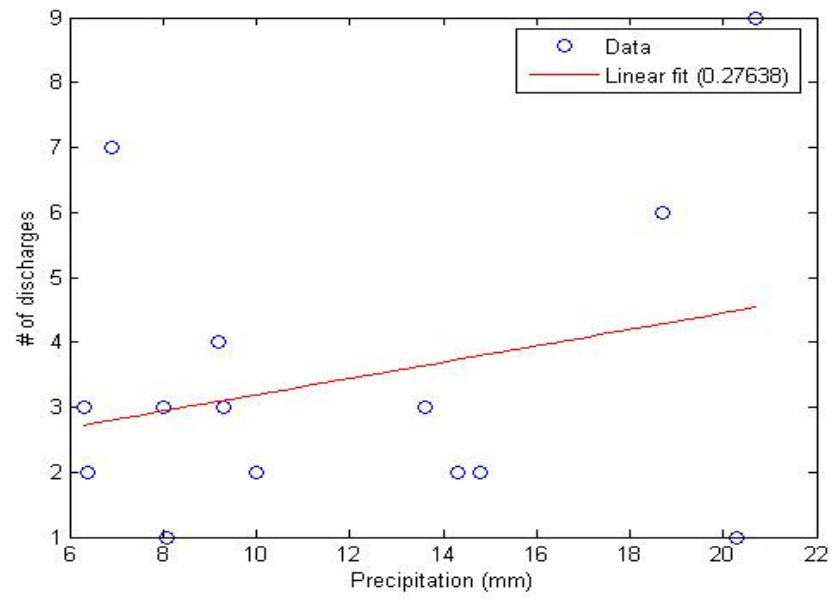

(a)

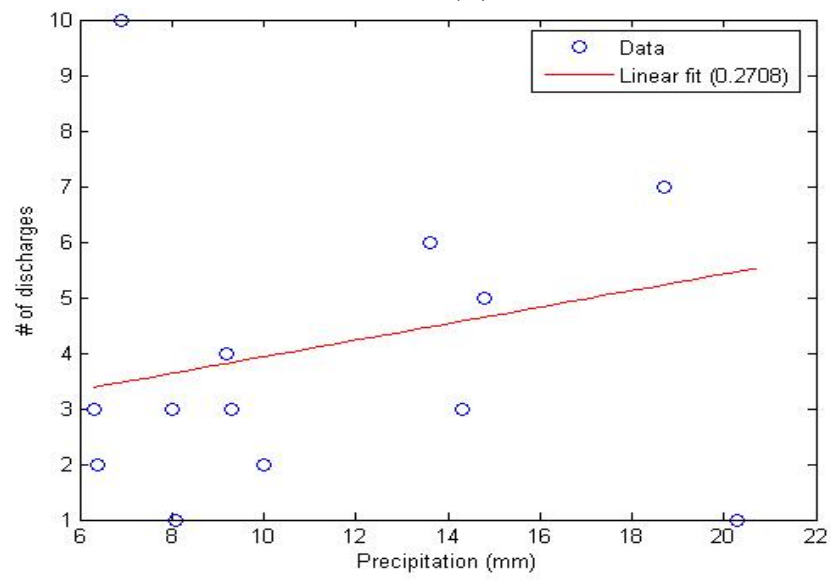

(b)

Fig. 4. Relationship between lightning and rainfall on 18 October 2006 for radius $10 \mathrm{~km}$ with time-lag (a) $5 \mathrm{~min}$ and (b) $10 \mathrm{~min}$.

The classification of these events is summarized in Table 2. The major synoptic futures associated with the warm period events are the surface seasonal low pressure (monsoonal), associated with an upper level trough that can lead to local convection. As for the cold period events, three variants of the accompanying frontal depression were noted: five events for which the major synoptic characteristic is a frontal depression invading in the area from the west; one event with a depression extending from the east; and five events in which the (relatively) low pressure over the area is a manifestation of the presence of a surface trough.

Gungle and Krider (2006) studied the relationship between lightning and rainfall for warm-season thunderstorms in Florida, USA; they concluded that a linear relationship could be found since, in the events they studied, there was a roughly constant rain volume per cloud-to-ground flash and therefore cloud-to-ground lightning can be used to estimate the location and intensity of convective rainfall under that 
Table 2. Classification of events into warm and cold period systems.

\begin{tabular}{ll}
\hline Type of event & Event number (Figs. 8, 9 and 10) \\
\hline Warm period events & $1,2,3,5,6,10,14,16$ \\
Cold period events & $4,7,8,9,11,12,13,15,17,18,19$
\end{tabular}

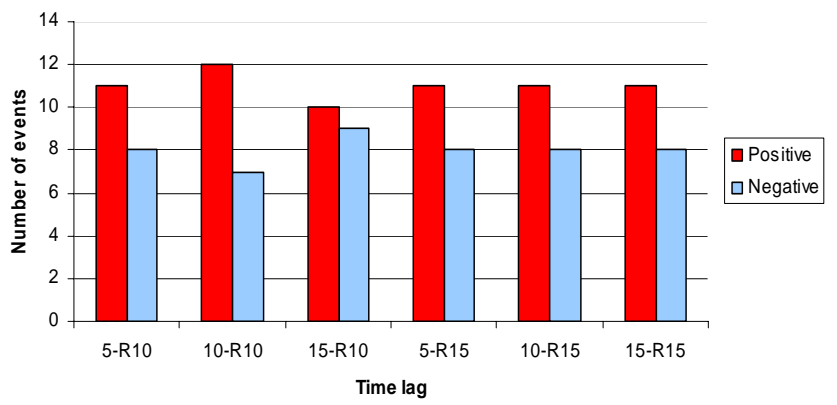

Fig. 5. The slope of the regression lines for the six schemes.

weather regime. Bearing in mind the above, the negative slopes found in the present study could be an indication that in the cases studied here the rainfall volume per lightning is highly variable.

In studying the correlations between lightning and rainfall, Soula and Chauzy (2001) noted that positive cloud-to-ground flashes are associated with higher rainwater volume than negative flashes and a correction on the basis of this finding improved the relationships established. In the present paper, there has been no distinction between positive and negative flashes and therefore the negative slopes could be, at least partly, ascribed to a dominance of the negative flashes in some cases.

Katsanos et al. (2007) discuss certain issues regarding the difficulties in the establishment of a linear relationship between lightning and rainfall. Their analysis focused on the wet season and covered a wider area in the eastern Mediterranean. They concluded that a linear relationship between rainfall and lightning was not possible.

Three events of the cold group had negative slope for the $15 \mathrm{~km}$ radius and positive for the $10 \mathrm{~km}$ radius. Two events of the warm group had negative slope for the $10 \mathrm{~km}$ radius and positive for the $15 \mathrm{~km}$ radius.

Bearing in mind that the amount of precipitation at the station does not change with changing radius, the different distribution of lightning within the circle around the station, might be the cause in the change of the sign of the slope, from positive to negative and vice versa. For example, in the cold group cases mentioned above, it appears that, for these cold group events, the lightning activity could be more concentrated around the station. Also, for the warm group events, it seems that a larger area is required to take all of the corresponding lightning into account, implying that the lightning

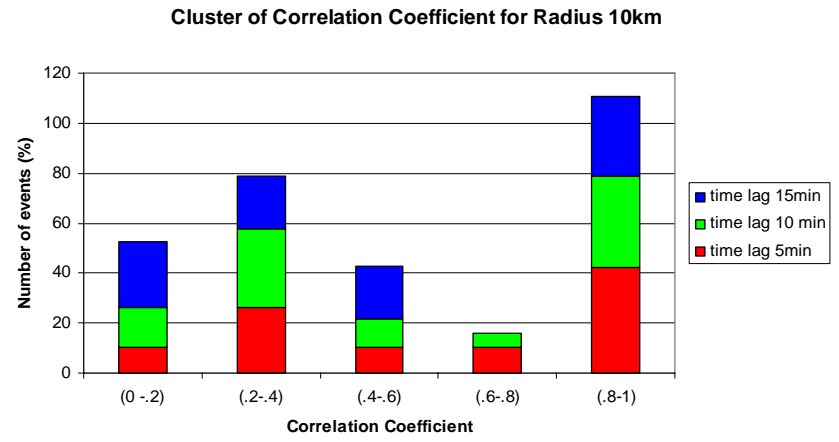

Fig. 6. The percentage of the events per time lag and for a radius of $10 \mathrm{~km}$.

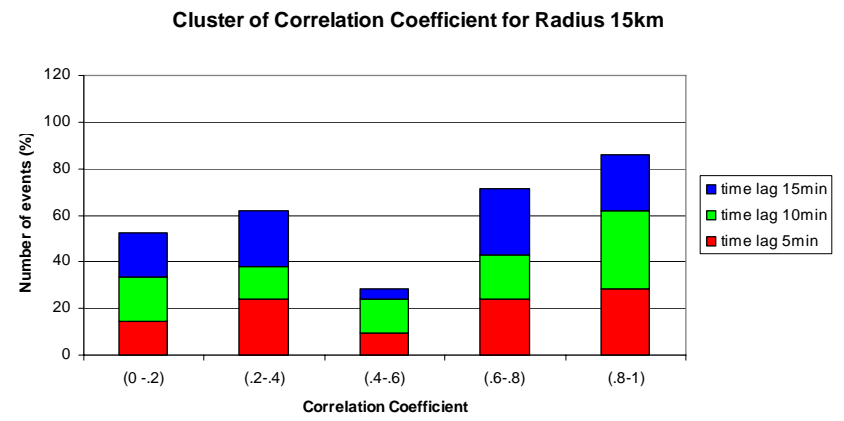

Fig. 7. The percentage of the events per time lag and for a radius of $15 \mathrm{~km}$.

activity related to precipitation could be more spread away from the station.

\subsection{Correlation coefficient}

The values of the correlation coefficient were classified into five clusters; $(0-0.2),(0.2-0.4),(0.4-0.6),(0.6-0.8)$ and $(0.8-1)$; this choice is arbitrary, but can be related to very low, low, medium, good and very good correlation, respectively.

The percentage of the events per time lag and for a radius of $10 \mathrm{~km}$ is shown in Fig. 6. The majority of the events were associated with correlation coefficients ranging from 0.8 to 1 and from 0.2 to 0.4 . As the time lag increases, the values for the correlation coefficient of 13 events remained roughly unchanged, while in five events the values were lower and in one event the value was higher.

Also, most of the events for the $15 \mathrm{~km}$ radius were associated with correlation coefficients with values ranging between 0.8 to 1 and 0.6 to 0.8 (Fig. 7). As the time lag increases, the values for the correlation coefficient of thirteen of the events studied remain unchanged, while in four events the values were lower and in two events the values were higher.

From the above, it is evident that the best time lag between the rainfall and the lightning data is the lowest, namely, $5 \mathrm{~min}$. 
Change of the Correlation Coefficient per event for time lag $5 \mathrm{~min}$

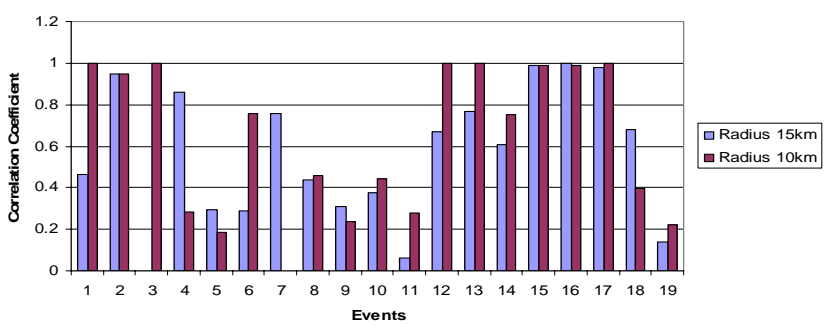

Fig. 8. The correlation coefficient for each event with a radius of $10 \mathrm{~km}$ (in purple) and with a radius of $15 \mathrm{~km}$ (in blue) and a time lag of $5 \mathrm{~min}$.

Change of the Correlation Coefficient per events for time lag 10min

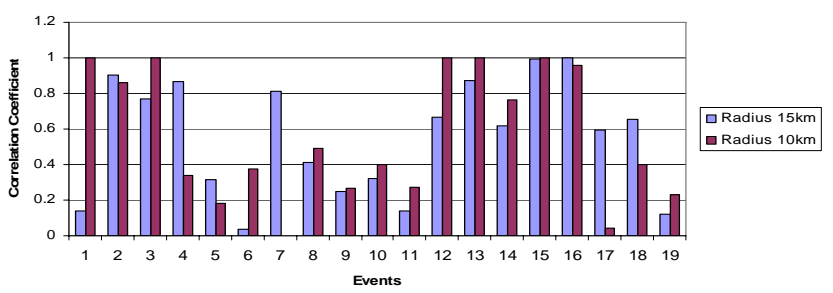

Fig. 9. The correlation coefficient for each event with a radius of $10 \mathrm{~km}$ (in purple) and with a radius of $15 \mathrm{~km}$ (in blue) and a time lag of $10 \mathrm{~min}$.

\subsection{Changes of the correlation coefficient with the change of radius for the same time lag}

In Figs. 8, 9 and 10, the values of the correlation coefficient between the lightning and rainfall data, for each event are shown for the radius of $10 \mathrm{~km}$ (in purple) and for the radius of $15 \mathrm{~km}$ (in blue) and with a time lag of 5, 10 and $15 \mathrm{~min}$, respectively.

For time lag of $5 \mathrm{~min}$ and with the increase in radius from 10 to $15 \mathrm{~km}$, the correlation coefficient decreased in nine of the events, increased in five and in the remaining five it remained roughly unchanged.

For time lag of $10 \mathrm{~min}$ and with the increase in radius, the correlation coefficient presented a decrease in ten of the events, in five of the events presented an increase and in the rest for events the change was not significant.

For time lag of $15 \mathrm{~min}$, the increase in radius resulted in a decrease of the correlation coefficient in ten of the events, in an increase in five of the events, whereas in the rest for events the change was not significant.

It can be concluded from the above that the optimum radius for all of the three time lags is $10 \mathrm{~km}$.

It should be noted here that by changing the time lag from 5 to $10 \mathrm{~min}$, five events noted a significant change in the correlation coefficient; those of 2 October 2006, 5 July 2006, 7 July 2006, 18 October 2006 and 29 September 2005. By changing the time lag again, this time from 10 to $15 \mathrm{~min}$,
Change of the Correlation Coefficient per events for time lag 15min

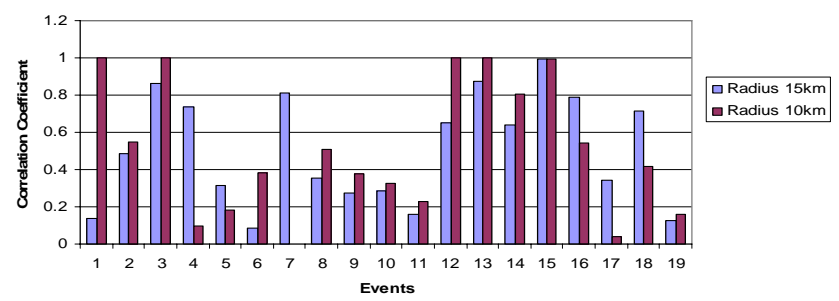

Fig. 10. The correlation coefficient for each event with a radius of $10 \mathrm{~km}$ (in purple) and with a radius of $15 \mathrm{~km}$ (in blue) and a time lag of $15 \mathrm{~min}$.

three events noted a significant change in the correlation coefficient, namely, on 4 August 2005, 28 May 2005 and 6 February 2006.

For the $10 \mathrm{~km}$ radius, eleven events exhibit consistently high values of the correlation coefficient: six events belong to the warm period group and five events belong to the cold period group. The remaining eight events exhibit low values of the correlation coefficient: two events belong to the warm period group and six events belong to the cold period group.

For the $15 \mathrm{~km}$ radius, twelve of the events exhibit consistently high values of the correlation coefficient: four events belong to the warm period group and the eight events belong to the cold period group. The remaining seven events exhibit low values of the correlation coefficient; four events belong to the warm period group and three events belong to the cold period group.

For both radii and for all time lags, eight events show high values of the correlation coefficient: four events belong to the warm period group and the other four events belong to the cold period group.

Summarising the above, it is evident that the majority of the convective events (6 out of 8) show high values of the correlation coefficient for the $10 \mathrm{~km}$ radius while the majority of frontal events ( 8 out of 11) show high values of the correlation coefficient for the $15 \mathrm{~km}$ radius. This result may reflect the size (horizontal dimensions) of the cumulonimbus cloud under different conditions.

\section{Conclusions}

The objective of this study was to identify relationships between lightning and rainfall data, adopting a statistical methodology. The data used were the hourly rainfall data from the rain gauge network of the Cyprus Meteorological Service and the corresponding ZEUS lightning data. The stations with rainfall less than $5 \mathrm{~mm}$ per hour were removed and not considered for further study. The rainfall stations were considered to be the centre of circles of a radius of 10 and $15 \mathrm{~km}$, while the time lag between the number of lightning within the selected radius and the rainfall recorded at the 
station, were of 5, 10 and $15 \mathrm{~min}$. The possible relationships were calculated by the GAMA software for a total of 19 rain events. The fitted regression between rainfall and lightning data was considered to be linear. A number of cases had a negative slope and an attempt was made to provide a rather qualitative explanation.

The classification of the values of the correlation coefficient showed that, for a radius of $10 \mathrm{~km}, 42 \%$ of the events have values between 0.8 and 1 , which was the perfect correlation between the rainfall and the lightning data. This percentage decreases as the time lag increases; $37 \%$ for the time lag of $10 \mathrm{~min}$ and $32 \%$ for the time lag of $15 \mathrm{~min}$. When the radius of $15 \mathrm{~km}$ is in effect, the corresponding percentage was much smaller; $29 \%, 33 \%$ and $24 \%$, respectively. Also, the best correlation between the rainfall and lightning data was achieved, for all three time lags, in the case of the circle with a radius of $10 \mathrm{~km}$, which is comparable to the typical size of thunderstorm cells developing over the area.

The events studied in the present paper and especially those with negative slope, will be further investigated by the authors in future work. Such future work is planned to include a better selection of the convective type events by using thermodynamic criteria. Thermodynamic indices may also be used as independent variables in a multiple regression analysis.

Acknowledgements. This study was undertaken within the framework of Project "FLASH" which is funded by the European Union (Sixth Framework Programme, Contract No. 036852). The authors wish to thank K. Lagouvardos and V. Kotroni of the National Observatory of Athens, Greece for providing the lightning data and Maria-Carmen Llasat and her collaborators from the Meteorological Hazards Analysis Team, Department of Astronomy \& Meteorology, Faculty of Physics, University of Barcelona, Spain for making available the relZeus software.

Edited by: A. Orphanou

Reviewed by: D. Katsanos and another anonymous referee

\section{References}

Altaratz, O., Levin, Z., Yair, Y., and Ziv, B.: Lightning activity over land and sea on the eastern coast of the Mediterranean, Mon. Weather Rev., 131, 2060-2070, 2003.

Ezcurra, A., Areitio, J., and Herrero, I.: Relationships between cloud-to-ground lightning and surface rainfall during 1992-1996 in the Spanish Basque Country area, Atmos. Res., 61, 239-250, 2002.

Gungle, B. and Krider, E. P.: Cloud-to-ground lightning and surface rainfall in warm-season Florida thunderstorms, J. Geophys. Res., 111, D19203, doi:10.1029/2005JD006802, 2006.

Katsanos, D., Lagouvardos, K., Kotroni, V., and Argiriou, A.: Combined analysis of rainfall and lightning data produced by mesoscale systems in the central and eastern Mediterranean, Atmos. Res., 83, 55-63, 2007.

Kotroni, V. and Lagouvardos, K.: Lightning occurrence in relation with elevation, terrain slope, and vegetation cover in the Mediterranean, J. Geophys. Res., 113, D21118, doi:10.1029/2008JD010605, 2008.

Lagouvardos, K., Kotroni, V., Betz, H.-D., and Schmidt, K.: A comparison of lightning data provided by ZEUS and LINET networks over Western Europe, Nat. Hazards Earth Syst. Sci., 9, 1713-1717, doi:10.5194/nhess-9-1713-2009, 2009.

Lang, T. J. and Rutledge, S. A.: Relationships between Convective Storm Kinematics, Precipitation, and Lightning, Mon. Weather Rev., 130, 2492-2506, 2002.

Michaelides, S. C., Savvidou, K., Nicolaides, K. A., and Charalambous, M.: In search for relationships between lightning and rainfall with a rectangular grid-box methodology, Adv. Geosci., 20, 51-56, 2009, http://www.adv-geosci.net/20/51/2009/.

Morales, C. A., Anagnostou, E. N., Williams, E., and Kriz, J. S.: Evaluation of Peak Current Polarity Retrieved by the ZEUS Long-Range Lightning Monitoring System, IEEE Geosci. Remote S., 4, 32-36, 2007.

Piepgrass, M. V. and Krider, E. P.: Lightning and surface rainfall during Florida thunderstorms, J. Geophys. Res., 87, 193-201, 1982.

Rivas Soriano, L., de Pablo, F., and García Díez, E.: Relationship between convective precipitation and Cloud-to-Ground lightning in the Iberian Peninsula, Mon. Weather Rev., 129, 2998-3003, 2001.

Soula, S. and Chauzy, S.: Some aspects of the correlation between lightning and rain activities in thunderstorms, Atmos. Res., 56, 355-373, 2001.

Soula, S., Sauvageot, H., Molinié, G., Mesnard, F., and Chauzy, S.: The CG lightning activity of storm causing a flashflood, Geophys. Res. Lett., 25, 1181-1184, 1998.

Tapia, A. and Smith, J. A.: Estimation of Convective Rainfall from Lightning Observations, J. Appl. Meteorol., 37, 14971509, 1998.

Uman, M. A.: The Lightning Discharge, Academic Press, 377 pp., 1987. 